\title{
El rol de los bañados de desborde fluvial en la retención de nutrientes y su actividad metabólica
}

\author{
Joaquín Cochero ${ }^{1,2}$, Hugo Di Giorgl ${ }^{1}$, Jorge Donadelli ${ }^{1,2}$, Jimena Suárez ${ }^{1}$,2, Ramiro \\ Simonetti', Nícolas Reinaldo Finkler ${ }^{3}$, Daví Gasparini Fernandes Cunha ${ }^{3}$ \\ 'Instituto de Limnología “Dr. Raúl A. Ringuelet" (CONICET-UNLP), La Plata, Buenos Aires, Argentina \\ ${ }^{2}$ CONICET, Consejo Nacional de Investigaciones Científicas y Tecnológicas, La Plata, Argentina \\ ${ }^{3}$ Departamento de Hidráulica e Saneamento, Escola de Engenharia de São Carlos, Universidade de São \\ Paulo, Brasil
}

E-mail: jcochero@ilpla.edu.ar

\begin{abstract}
RESUMEN. El objetivo de este trabajo fue analizar los efectos de los bañados de desborde fluvial sobre la calidad del agua y el metabolismo del curso de agua. Para ello se estudiaron cuatro cauces, dos que recorren la periferia de un casco urbano y que tienen zonas de bañados de desborde fluvial conservados, y que mantienen su conexión con el agua subterránea, y otros dos periurbanos y que sus bañados de desborde fluvial han sido degradados por el avance de la urbanización, desconectándolos de las capas freáticas. En cada uno, se muestrearon tres tramos de 50 metros de longitud. El primero, localizado aguas arriba de la zona de bañados (llamado "Arriba"), el segundo en el tramo medio del curso de agua que recorre el bañado (llamado "Medio"), y el último aguas abajo del bañado (llamado "Abajo"). Las variables estudiadas incluyeron, en cuatro períodos del año y en cada tramo, parámetros físico-químicos (temperatura, conductividad, pH, oxígeno disuelto, turbidez, sólidos disueltos y suspendidos, concentraciones de formas del nitrógeno y fósforo disuelto y total) y biológicos, vinculados a la actividad metabólica del biofilm y a la densidad de bacterias. Además, en dos momentos del año, se realizaron ensayos de retención de nutrientes y metabolismo fluvial en los tramos medios de los cursos fluviales. Los resultados muestran que los bañados de desborde fluvial mejor conservados a) disminuyen significativamente el oxígeno disuelto y aumentan la concentración de sólidos suspendidos en el cauce; b) incrementan significativamente los procesos metabólicos fluviales, tales como la respiración o la producción primaria; c) poseen tasas elevadas de asimilación de nutrientes por la biota; d) actúan como depuradores de bacterias coliformes en el cauce principal. Estos patrones generales pueden ser detectados aunque se observa mucha variabilidad en los cauces, y su intensidad varía a lo largo del año y en función de las condiciones físico-químicas del flujo.
\end{abstract}

Palabras clave: Autodepuración, metabolismo fluvial, retención de nutrientes.

ABSTRACT. The aim of this work was to analyze the effects of riverine wetlands on the water quality and river metabolism. For this purpose, four streams were studied: two of them surround a periurban area and have well-preserved riverine wetlands associated with the main channel, and the other two run through an urban area with the consequent degradation of their riverine wetlands by urban development. In each stream, three sections 50 meters long were sampled. The first one, located upstream of the riverine wetland zone (called "Arriba"), the second in the middle section of the water course that runs through the riverine wetland zone (called "Medio"), and the last one downstream of the riverine wetland zone (called "Abajo"). The variables studied included, in four 
periods of the year and in each section: physical-chemical parameters (temperature, conductivity, $\mathrm{pH}$, dissolved oxygen, turbidity, dissolved and suspended solids, concentrations of nitrogen forms, and total and dissolved phosphorous) and biological parameters, linked to the metabolic activity of the biofilm and bacterial densities. In addition, at two sampling times, nutrient retention experiments were carried out in the middle section of the stream courses, using the tracer addition technique to characterize the nutrient spiral. The results show that the best preserved riverine wetlands a) significantly decrease dissolved oxygen and increase the concentration of suspended solids in the channel; b) act as sinks for $\mathrm{P}$ and $\mathrm{N}$, increasing fluvial metabolic processes, such as respiration or primary production; c) result in high rates of assimilation of nutrients by the biota; and d) act as retention zones for coliform bacteria in the main channel. These general patterns can be detected in all systems, although much variability is observed in the channels, and their intensity varies throughout the year and depending on the physical-chemical conditions of the flow.

Keywords: Fluvial metabolism, nutrient retention, self-depuration.

\section{INTRODUCCIÓN}

La hidrología, biogeoquímica y ecología de los ríos es modificada en muchos casos por la interacción con su planicie aluvial. En grandes ríos, el ecosistema de la planicie aluvial difiere del ecosistema del cauce, pero su química tanto como sus comunidades bióticas se relacionan con los ciclos de inundación de los ríos (Junk, 2005; Marchetti \& Aceñolaza, 2012; Tockner, 2002). La interacción entre el cauce principal y su planicie de inundación es responsable de grandes cambios en la calidad del agua, principalmente referidos a la retención de sedimentos, consumo de oxígeno, enriquecimiento con $\mathrm{CO}_{2}$, liberación de carbono orgánico disuelto, y transformación y/o pérdida de nutrientes inorgánicos (Tockner, 2002; Villar \& Bonetto, 2000).

El vínculo entre el cauce principal y su planicie aluvial es determinante para entender el funcionamiento de un río y, entonces, poder generar estrategias de manejo de su cuenca. Un aspecto clave en la dinámica de los ríos con relación al éxito de los programas de restauración es su capacidad de autodepuración, en lo que respecta a la calidad del agua, lo que permite establecer la magnitud de los efectos de los tratamientos en el tiempo y en la distancia (Dzyuban, 2003; Parkyn et al., 2003). La capacidad de autodepuración en ecosistemas acuáticos está basada en ciertas características principales: a) la degradación de compuestos orgánicos por actividad microbiana (Nishihama et al., 2008); b) la adsorción de xenobióticos y metales pesados en los suelos riparios y en los sedimentos (Hunter et al., 2009), y c) la asimilación de nutrientes por la vegetación riparia y acuática (Barton \& Northup, 2011; McIntyre et al., 2009). La capacidad de autodepuración se ve modificada por factores naturales y antrópicos que afectan distintos aspectos de los sistemas lóticos tales como su contenido de nutrientes, $\mathrm{C}$ orgánico y $\mathrm{O}_{2}$ disuelto (Carey \& Migliaccio, 2009), que a su vez interactúan con la actividad y abundancia microbiana, alterando las tasas naturales de depuración (Carey \& Migliaccio, 2009; Dzyuban, 2003; Kosolapov et al., 2003; Perryman et al., 2011).

En sistemas fluviales, los arroyos de bajo orden contribuyen significativamente a la remoción de $\mathrm{N}$ y a la depositación de $\mathrm{P}$, dado que a través de ellos ingresa al cauce la mayor parte de la escorrentía superficial (Wollheim et al., 2014). En estos arroyos hay gran actividad biológica debido a la mayor relación entre la superficie béntica y el volumen de agua suprayacente que conduce generalmente a mayor contacto e intercambio (Alexander et al., 2008).

Sin embargo, a medida que la provisión de nutrientes excede la capacidad de asimilación de la comunidad biológica una gran proporción del ingreso es transferido aguas abajo 
(Mulholland et al., 2008; Wollheim et al., 2008). La asimilación y retención de nutrientes ocurre desproporcionadamente en las zonas transitorias de almacenamiento, aquellas con mayor tiempo de residencia del agua en relación a la vaguada, dónde se facilita el contacto de los reactivos solubles con la microbiota incrementándose su procesamiento biogeoquímico (Mulholland \& De Angelis, 2000; Runkel, 2007). En humedales, en los que la zona transitoria de almacenamiento representa una importante área en relación a la sección, la retención de nutrientes y sedimentos es muy importante. Estos ambientes también pueden actuar como filtros reteniendo bacterias provenientes de la ganadería (Knox et al., 2008), y se han evidenciado retenciones de entre 80 y 99\% de Escherichia coli y coliformes fecales en humedales superficiales construidos para tratar aguas residuales municipales y de la ganadería (Gerba et al., 1999; Hill, 2003).

En ríos y arroyos pequeños, estas zonas transitorias de almacenamiento están bien representadas por los bañados de desborde fluvial (BDF) que conforman parte de su cauce en zonas de baja pendiente. La interacción entre grandes ríos y sus llanuras de inundación ha sido estudiada abordando los diferentes componentes biogeoquímicos del agua, pero es escasa la información sobre el efecto de los pequeños bañados de desborde fluvial sobre los procesos de autodepuración de cursos de agua de bajo orden.

El objetivo de este trabajo es analizar los efectos de los BDF sobre la calidad del agua y el metabolismo fluvial. Para ello se estudiaron cuatro cauces, dos ubicados en áreas rurales con ganadería extensiva y con sus BDF bien preservados en estado natural, y otros dos ubicados en las zonas periurbanas de la ciudad de La Plata y cuyos BDF han sido degradados por el avance de la urbanización. Hipotetizamos que el cauce de un arroyo con un BDF mejor conservado contribuirá a la remoción de $\mathrm{N}$ y $\mathrm{P}$, por lo que las concentraciones de estos nutrientes aguas abajo del bañado disminuirán. También, los tramos con BDF mejor conservados tendrán una mayor densidad bacteriana y un metabolismo fluvial más activo, evidenciado por tasas de producción y respiración más elevadas.

\section{MATERIALES Y MÉTODOS Área de estudio}

Se seleccionaron cuatro cursos de agua de primer o segundo en la periferia del casco urbano de la ciudad de La Plata. Dos de ellos, los arroyos Chubichaminí ( $\left.35^{\circ} 7^{\prime} 44.50^{\prime \prime} \mathrm{S}, 57^{\circ} 41^{\prime} 51.95^{\prime \prime} \mathrm{O}\right)$ y Cajaravillas ( $35^{\circ} 2^{\prime} 45.90^{\prime \prime} \mathrm{S}, 57^{\circ} 48^{\prime} 44.01^{\prime \prime} \mathrm{O}$ ), recorren una zona ganadera de producción extensiva, y tienen BDF bien preservados que conservan su conexión con el agua subterránea. Los otros dos, los arroyos del Gato (34 ${ }^{\circ} 58^{\prime} 56.58^{\prime \prime}$ S, 58 $8^{\circ} 13.13^{\prime \prime}$ O) y Carnaval $\left(34^{\circ} 55^{\prime} 2.24^{\prime \prime} \mathrm{S}\right.$, $58^{\circ} 6^{\prime} 30.53^{\prime \prime}$ O), han sido encauzados y sus BDF han sido modificados como consecuencia de las actividades antrópicas vinculadas a la producción hortícola y la urbanización, y se han desvinculado del agua subterránea por la extracción excesiva de agua en la región.

En cada cauce se delimitaron tres tramos, de unos 50 metros de longitud cada uno: un tramo en el cauce principal, dentro de la zona de BDF (Medio), y otros dos tramos sobre el cauce principal, fuera de la zona de BDF: un tramo aguas arriba (Arriba) y otro tramo aguas abajo (Abajo). Entre tramos hubo una distancia mínima de 100 metros, adonde no se encontraron fuentes puntuales de ingreso de nutrientes.

En cuatro muestreos (marzo 2017, junio 2017, septiembre 2017, febrero 2018) se colectaron en cada tramo muestras de agua y sedimento por triplicado para la medición de variables físicoquímicas y biológicas. Además, se realizaron dos ensayos in situ (septiembre 2017 y febrero 2018) para medir el metabolismo fluvial y la capacidad de retención de nutrientes en cada tramo Medio.

\section{Parámetros físicos y químicos}

Se midió in situ pH, conductividad ("Cond", mS/ $\mathrm{cm}$ ), turbidez ("Turb", UNT), temperatura ("Temp", ${ }^{\circ} \mathrm{C}$ ), concentración de oxígeno disuelto ("OD", $\mathrm{mg} / \mathrm{L}$ ), potencial redox ("ORP") y concentración de sólidos disueltos totales ("SDT", mg/L) con un sensor multiparamétrico Horiba U80. Se midió también los sólidos suspendidos totales ("SST", mg/L) mediante técnicas estándar (APHA, 2012). 
En cada tramo se colectaron muestras de agua $(250 \mathrm{~mL}$ ) por triplicado, que se mantuvieron a $4^{\circ} \mathrm{C}$ hasta su filtrado en el laboratorio el mismo día. Las muestras fueron filtradas utilizando filtros tipo Whatman GF/C y conservadas a $-18^{\circ} \mathrm{C}$ hasta su análisis. Las concentraciones (mg/L) de $\mathrm{NH}_{4}^{+}, \mathrm{NO}_{3}^{-}$- y $\mathrm{NO}_{2}^{-}$y fósforo reactivo soluble ("PRS", $\mathrm{mg} / \mathrm{L}$ ) fueron determinadas aplicando metodología estándar (APHA, 2012). También se colectaron muestras de agua por triplicado para la determinación de fósforo total ("Ptotal", mg/L), nitrógeno total ("Ntotal", mg/L), demanda bioquímica de oxígeno ("DBO", $\mathrm{mg} / \mathrm{L}$ ) y demanda química de oxígeno ("DQO", $\mathrm{mg} / \mathrm{L}$ ) por metodología estándar (APHA, 2012).

\section{Actividad metabólica del sedimento}

Se colectaron muestras de sedimento con un aspirador (5 réplicas de $1 \mathrm{~cm}$ de diámetro, de $0,5 \mathrm{~cm}$ de profundidad) para analizar la respiración de la capa superficial del sedimento. La actividad del sistema transportador de electrones (STE), una medida de la respiración total del biofilm, fue ensayada mediante la reducción del aceptor de electrones INT (2-3 tetrazolium chloride) a INT-Formazan (iodonitrotetrazolium formazan) (Blenkinsopp \& Lock, 1990). Las muestras se incuban en una solución 0,02\% de INT (Sigma-Aldrich) por 12h en la oscuridad. El INT-Formazan se extrae luego con metanol frío durante una hora a $4^{\circ} \mathrm{C}$ en la oscuridad, y luego las muestras se sonicaron en un baño de ultrasonido (Cleanson CS1106). Finalmente se midió absorbancia a $480 \mathrm{~nm}$ con un espectrofotómetro Labomed UV-VIS Auto 2602, que se convirtió a concentración de actividad de STE (g INT-formazan $/ \mathrm{cm}^{2} \mathrm{~h}$ ) usando como referencia una solución patrón de $30 \mathrm{mg} / \mathrm{mL}$ de INT-formazan en metanol.

\section{Metabolismo fluvial}

Se estimó el metabolismo fluvial de cada tramo Medio, en condiciones de flujo basal, midiendo las variaciones diarias de la concentración de oxígeno disuelto (OD), temperatura del agua, e intensidad de la luz a intervalos de 10 minutos durante períodos de 1-3 días, utilizando registradores de oxígeno disuelto con sensor óptico (Onset-HOBO® U26-001) y de luz y temperatura (Onset-HOBO ${ }^{\circledR}$ UA-00264). Los sensores de oxígeno fueron calibrados al aire antes de cada despliegue, y a posteriori para corregir los datos. Se estimó producción primaria bruta (PPB), producción primaria neta (PPN) y respiración ecosistémica (RE) ajustando un modelo de una estación a las curvas diarias de $\mathrm{O}_{2}$, siguiendo a Riley \& Dodds (2013).

\section{Retención de nutrientes}

Para estimar las métricas de retención de nutrientes se utilizó el método de Adición de Trazadores para la Caracterización de Curvas en espiral ("TASCC", Covino et al., 2010). A partir de la adición de un pulso de nutrientes se estimó la proporción de áreas de almacenamiento de transición (As) sobre el área media (A), las distancias de asimilación (SWamb) y las tasas de asimilación (Uamb) para $\mathrm{NH}_{4}{ }^{+} \mathrm{y} \mathrm{PO}_{4}{ }^{3-}$ (Stream Solute Workshop, 1990).

Se agregaron simultáneamente $\mathrm{NH}_{4}{ }^{+}$(como $\mathrm{NH}_{4} \mathrm{Cl}$ ) y $\mathrm{PO}_{4}^{3-}$ (como $\mathrm{K}_{2} \mathrm{HPO}_{4}$ ), ambos trazadores reactivos para caracterizar la dinámica de nutrientes, y $\mathrm{Cl}^{-}$(como $\mathrm{NaCl}$ ) como trazador conservativo para considerar la dilución y caracterizar la hidrodinámica del cauce. La masa añadida del trazador conservativo fue calculada a priori para incrementar la conductividad eléctrica a niveles detectables (5-10 veces la concentración basal), mientras que la masa añadida de nutrientes fue calculada para elevar la concentración basal del arroyo 2-5 veces (Corvino et al., 2010). En cada tramo, se disolvieron todas las sales en un balde con $5 \mathrm{~L}$ de agua del arroyo y se realizó una adición puntual en el comienzo del tramo durante un minuto. La conductividad fue medida durante el experimento al final del tramo, donde se tomaron muestras de agua durante el avance del pulso, con una frecuencia de muestreo en función de la tasa de aumento de la conductividad eléctrica, resultando en 21-26 muestras de nutrientes por tramo muestreado. Inmediatamente antes de las adiciones se colectaron tres muestras de agua para obtener las concentraciones basales de nutrientes en el ambiente. Todas las muestras fueron filtradas inmediatamente $(\mathrm{GF} / \mathrm{C})$ y freezadas $\left(-18^{\circ} \mathrm{C}\right)$ hasta 
su análisis (APHA, 2012).

\section{Bacterias indicadoras de contaminación fecal}

Se realizó el recuento de Escherichia coli en las muestras analizadas utilizando la técnica de recuento en placas (EC Compact Dry) siguiendo las instrucciones del fabricante (Nissui Pharmaceutical. CO., LTD). Las placas se inocularon con $1 \mathrm{~mL}$ de la muestra (o dilución apropiada) y se incubaron durante 24 hs a $35 \pm 2^{\circ} \mathrm{C}$. Las colonias de color azul/violeta se contaron como E. coli mientras que colonias rojas/rosadas fueron consideradas como otras coliformes. El medio utilizado selecciona en base a los sustratos cromogénicos (ISO 93081: 2014) Magenta-GAL, sustrato de la enzima beta galactosidasa presente en bacterias coliformes, y X-GLUC, sustrato de la enzima beta glucuronidasa específica de $E$. coli. Las placas fueron fotografiadas y los recuentos, expresados como unidades formadoras de colonia por $100 \mathrm{~mL}$ (ufc/100 mL), se realizaron utilizando el software de análisis de imagen Open CFU (Geissmann, 2013).

\section{Análisis estadísticos}

Dentro de cada cauce fluvial se exploraron los gradientes en los parámetros físico-químicos en los cuatro muestreos por separado (marzo, junio y noviembre, febrero) mediante análisis de componentes principales (ACP, previa estandarización de los datos), incluyendo los datos de los tres tramos de cada cauce fluvial. Luego, con la finalidad de establecer las diferencias entre los parámetros físico-químicos (Temp, pH, Cond, OD, Turb, ORP, $\mathrm{NO}_{3} ; \mathrm{NO}_{2}$, $\mathrm{NH}_{4}^{+}$, PRS, Ntotal, Ptotal, DBO, DQO, SST, SDT), y entre las variables biológicas ( $E$. coli, actividad del STE) entre los tramos de cada cauce, se realizaron análisis multivariados de la varianza (MANOVA) con tres factores: CAUCE (factor fijo con cuatro niveles: Chubichaminí, Cajaravillas, del Gato, Carnaval), TRAMO (factor anidado en CAUCE con tres niveles: ARRIBA, MEDIO, ABAJO) y TIEMPO (factor fijo con cuatro niveles: marzo, junio, noviembre, febrero), siguiendo el modelo $[Y i j k=\mu+$ Caucei + Tramoj(i) + Tiempok + Errorijk $]$.
Previamente se comprobaron la normalidad con el test de Shapiro-Wilk (Shapiro \& Wilk, 1965) y la homogeneidad de varianzas mediante el test de Cochran (Cochran, 1951). Se utilizó el test post-hoc de Student-Newman-Keuls (SNK).

Todos los análisis fueron realizados con Rv3.5.2 en RStudio v1.2.5033. Los ACP fueron realizados con el paquete base stats y graficados con los paquetes ggplot2 y ggfortify.

\section{RESULTADOS}

Los valores promedio ( $\pm \mathrm{DS}$ ) de los parámetro físico-químico en los arroyo, determinados en los distintos sectores y en cada muestreo se pueden observar en las Tablas Suplementarias 1 y 2. Los resultados del análisis a tres vías (Cauce, Tramo y Tiempo) indican una interacción significativa entre los factores (Tramo (Cauce)*Tiempo; $p<0,05$ ) tanto en el análisis multivariado como en el análisis de cada una de las variables físicoquímicas individuales (Tabla 1), indicando que cada cauce se comporta de manera distinta en los distintos momentos del año. Con el objeto de mejorar su exposición en el texto, los resultados serán agrupados en parámetros físico-químicos medidos in situ (Temp, Cond, pH, OD, Turb, ORP, SDT, SST) y análisis de nutrientes y materia orgánica (N, P, DBO, DQO), a pesar de que provienen de los mismos análisis. En las Figuras 1 a 4 se exhiben los análisis de componentes principales para cada sistema en cada muestreo. Los vectores en negro indican aquellas variables que demostraron diferencias significativas en los análisis confirmatorios $(p<0,05)$, los vectores grises aquellas que no representan diferencias significativas.

\section{Parámetros físico-químicos in situ}

En el Chubichaminí (Figura 1), el tramo Arriba tuvo valores significativamente mayores de $\mathrm{OD}$ en marzo; de $\mathrm{pH}$ y Temperatura en junio; de Turbidez y OD en noviembre y; de OD, $\mathrm{pH}$ y ORP en febrero. El tramo Medio tuvo mayores valores de SST en marzo; de TDS y conductividad en junio, y; Turbidez y SST en febrero. Por su lado el tramo Abajo estuvo asociado con aumentos 
Tabla 1. Resultados (F-valor) de los análisis de la varianza multivariados (MANOVA) y los análisis univariados para los parámetros físico-químicos medidos en cada tramo en los cuatro muestreos realizados en los cuatro cauces fluviales. Diferencias significativas $(p<0.05)$ se indican con *.

Table 1. Results (F-value) of the multivariate analysis of variance (MANOVA) and the univariate analyses for the physical-chemical parameters measured at each reach in the four studied watersheds during all four sampling campaigns. Significant differences $(p<0.05)$ are indicated with *.

\begin{tabular}{lcccc}
\hline Variable & CAUCE & TIEMPO & TRAMO(CAUCE) & TRAMO(CAUCE)* TIEMPO \\
\hline MANOVA & $354,38^{*}$ & $1170,23^{*}$ & $17,64^{*}$ & $11,08^{*}$ \\
Temperatura & $1042,99^{*}$ & $8481,51^{*}$ & $38,39^{*}$ & $53,05^{*}$ \\
pH & $8,862^{*}$ & $68,477^{*}$ & $6,005^{*}$ & $8,921^{*}$ \\
Conductividad & $100,698^{*}$ & $5,006^{*}$ & 1,885 & $4,778^{*}$ \\
OD & $83,28^{*}$ & $148,22^{*}$ & $21,36^{*}$ & $18,44^{*}$ \\
Turbidez & $27,71^{*}$ & $53,27^{*}$ & $11,24^{*}$ & $23,97^{*}$ \\
ORP & $3221,26^{*}$ & $11830,4^{*}$ & $17,66^{*}$ & $857,89^{*}$ \\
SDT & $455,6^{*}$ & $14309,9^{*}$ & $15,8^{*}$ & $165,8^{*}$ \\
SST & $17,746^{*}$ & $48,577^{*}$ & $3,67^{*}$ & $8,717^{*}$ \\
PRS & $1445,34^{*}$ & $125,65^{*}$ & $58,8^{*}$ & $40,36^{*}$ \\
NO ${ }_{3}^{-}$ & $117,46^{*}$ & $466,83^{*}$ & $58,67^{*}$ & $36,42^{*}$ \\
NO ${ }_{2}^{-}$ & $360,43^{*}$ & $8,698^{*}$ & $154,691^{*}$ & $65,174^{*}$ \\
NH $_{4}{ }^{+}$ & $509,4^{*}$ & $264,19^{*}$ & $72,94^{*}$ & $131,88^{*}$ \\
Ptotal $^{\text {Ntal }}$ & $616,89^{*}$ & $54,13^{*}$ & $27,3^{*}$ & $17,85^{*}$ \\
Ntol $_{\text {DQO }}^{683,1^{*}}$ & $205,4^{*}$ & $70,8^{*}$ & $110^{*}$ \\
DBO & $326,83^{*}$ & $116,97^{*}$ & $23,2^{*}$ & $22,01^{*}$ \\
\hline
\end{tabular}

de: de TDS en marzo; de TDS, conductividad y de Temperatura y pH en febrero.

OD en junio; de Temperatura en noviembre y; En el Cajaravillas (Figura 2), el tramo Arriba tuvo

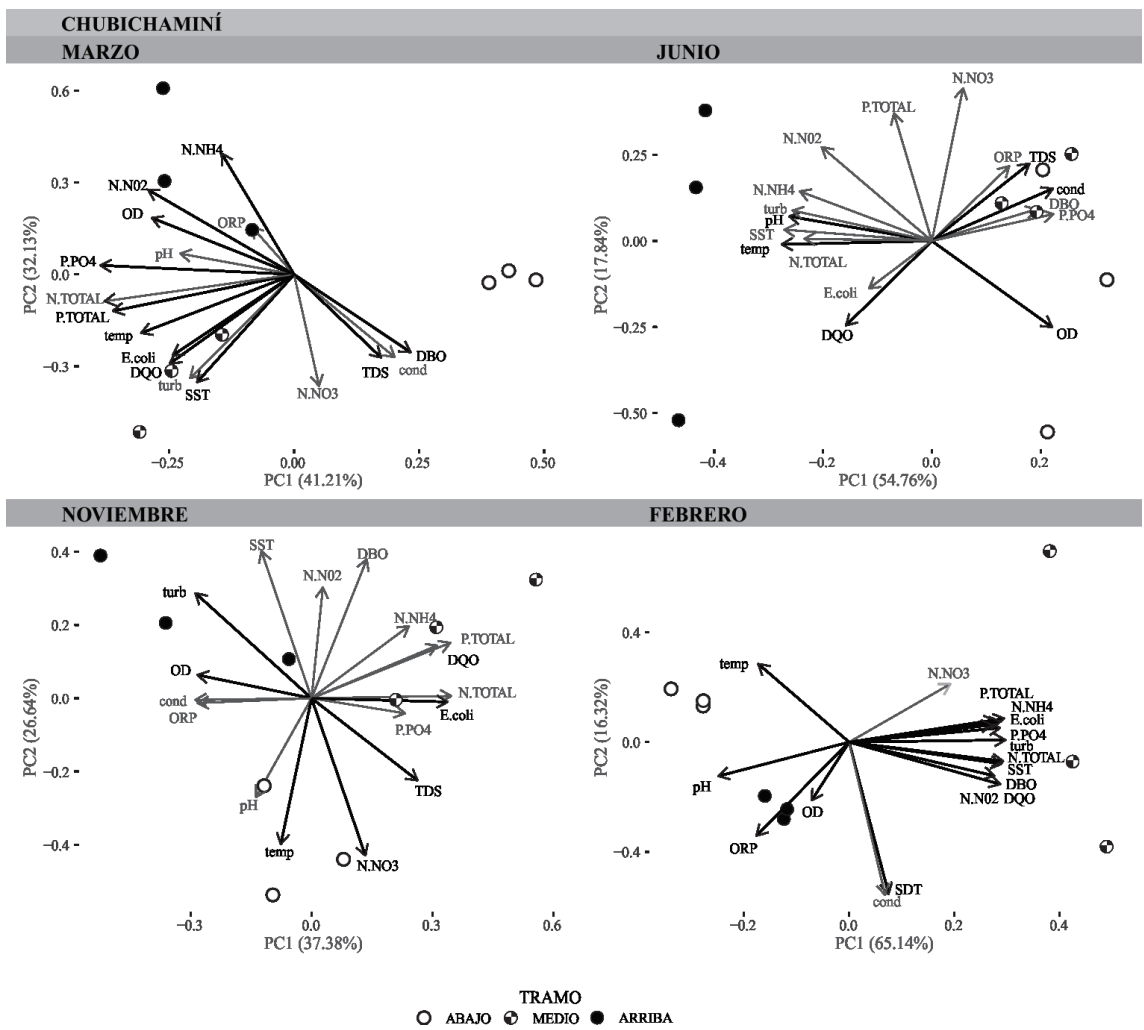

Figura 1. Resultados de los ACP para el cauce Chubichaminí, por cada período muestreado. Los vectores en negro representan aquellas variables significativas (MANOVA p <0.05) para diferenciar los tres tramos (Abajo, Medio, Arriba) en cada momento del año.

Figure 1. PCA results for the Chubichaminí watershed at each sampling period. Vectors in black represent significantly different variables (MANOVA, $p<0.05$ ) to differentiate each reach at each sampling time. 


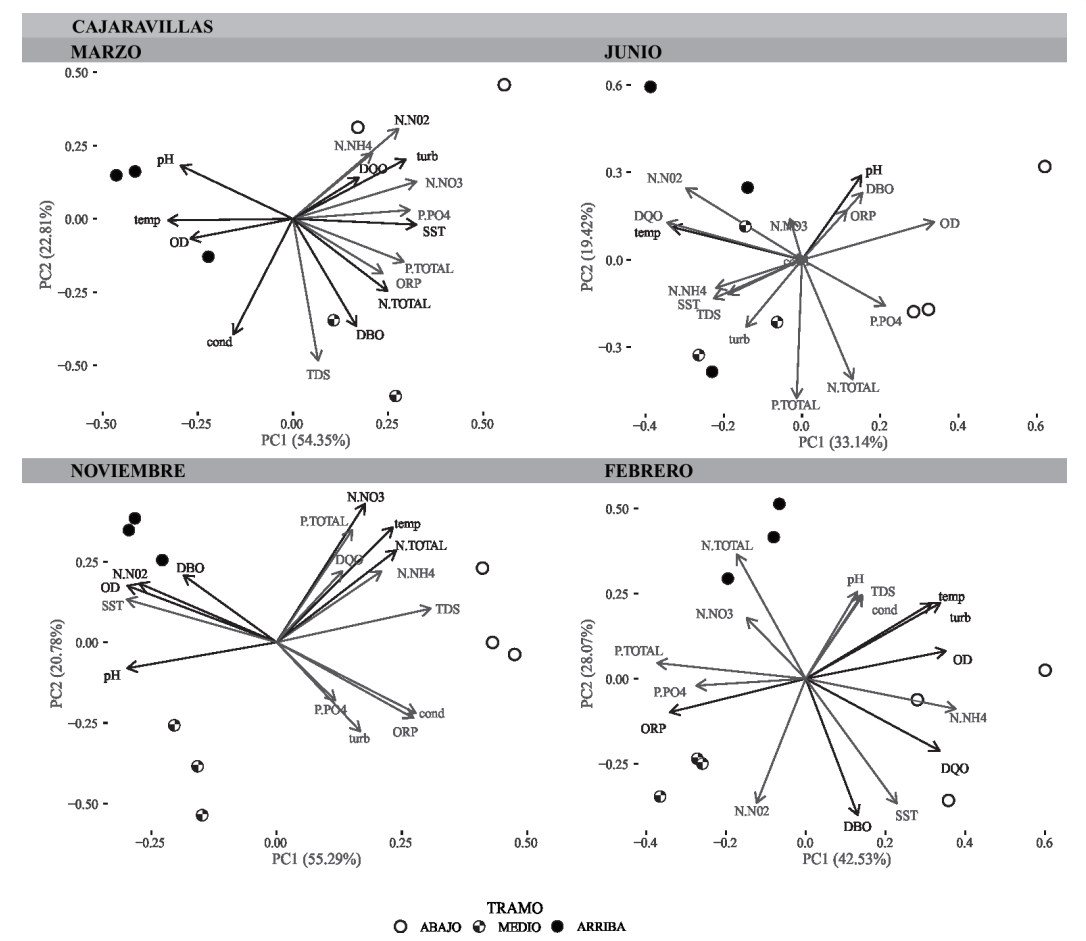

Figura 2. Resultados de los ACP para el cauce Cajaravillas, por cada período muestreado. Los vectores en negro representan aquellas variables significativas (MANOVA p<0.05) para diferenciar los tres tramos (Abajo, Medio, Arriba) en cada momento del año.

Figure 2. PCA results for the Cajaravillas watershed at each sampling period. Vectors in black represent significantly different variables (MANOVA, $p<0.05$ ) to differentiate each reach at each sampling time.

mayores valores $(p<0,05)$ de $\mathrm{pH}$, Temperatura y OD en marzo; aumentos de temperatura en junio e incrementos de OD y pH en noviembre. El tramo Medio tuvo los mayores valores de ORP en febrero $y$, al igual que en el tramo Arriba, la temperatura aumentó en junio. El tramo Abajo, por otro lado, se vinculó a los aumentos de Turbidez y SST en marzo; a la temperatura en noviembre y a aumentos de OD, Turbidez y Temperatura en febrero.

En el del Gato (Figura 3), el muestreo de febrero no pudo realizarse por la sequía extraordinaria del cauce. El tramo Arriba tuvo mayores valores de ORP en marzo, y una mayor conductividad y ORP en noviembre. El tramo Medio se vio asociado a mayores conductividades en marzo y en junio, cuando también tuvo aumentos de ORP, y en ese tramo también se midió un aumento de $\mathrm{pH}$ en noviembre. El tramo Abajo, por otro lado, se asoció a mayores valores de temperatura en marzo y en noviembre, $y$ aumentos significativos de OD en junio $y$ noviembre.

En el Carnaval (Figura 4), al igual que en el del Gato, el muestreo de febrero no pudo realizarse por efectos de la sequía. En marzo, el sitio Medio tuvo los mayores valores de SST y conductividad, mientras que en el sitio Abajo el $\mathrm{pH}$ fue la única variable que tuvo diferencias significativas, y únicamente en el muestreo de junio. En noviembre, el sitio Arriba se asoció a mayores valores de $\mathrm{pH}, \mathrm{OD}$ y Temperatura.

\section{Nutrientes y materia orgánica}

En el curso Chubichaminí (Figura 1) el tramo Arriba se vio relacionado con valores mayores de $\mathrm{NH}_{4}^{+}$y $\mathrm{NO}_{2}$ - durante marzo, y de DQO en junio. El tramo Medio estuvo asociado a valores mayores de nutrientes y materia orgánica en febrero (N, P, DBO, DQO), y de la DQO en marzo y en noviembre. El tramo Abajo, por otro lado, estuvo asociado a mayores valores de la DBO en marzo y de $\mathrm{NO}_{3}{ }^{-}$en noviembre.

En el Cajaravillas (Figura 2) en marzo los mayores valores de DBO y $\mathrm{N}$ total se asociaron al sitio Medio, y los de $\mathrm{DQO} \mathrm{NO}_{2}$ - al sitio Abajo. En noviembre, la DBO y la concentración de $\mathrm{NO}_{2}$-se asociaron al sitio Arriba, y los $\mathrm{NO}_{3}{ }^{-}$y el Ntotal al sitio Abajo. $Y$ en febrero el tramo Abajo estuvo relacionado a mayores valores de DBO y DQO. En el del Gato en marzo (Figura 3), los mayores 
Cochero et al.

$\begin{array}{lll}\text { DEL GATO } & \text { JUNIO } & \\ \text { MARZO } & 0 & 0 \\ & 0 & 0\end{array}$
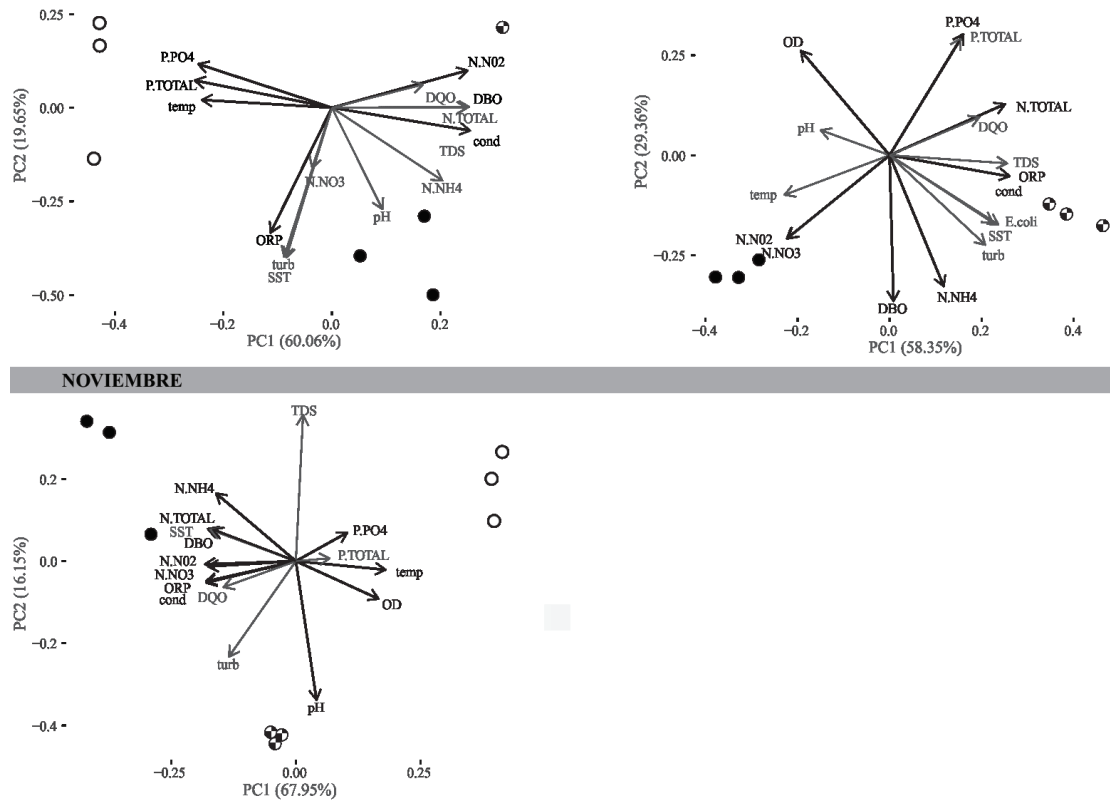

\section{O ABAJO MRAMO}

Figura 3. Resultados de los ACP para el cauce Gato, por cada período muestreado. Los vectores en negro representan aquellas variables significativas (MANOVA $\mathrm{p}<0.05$ ) para diferenciar los tres tramos (Abajo, Medio, Arriba) en cada momento del año.

Figure 3. PCA results for the Gato watershed at each sampling period. Vectors in black represent significantly different variables (MANOVA, $p<0.05$ ) to differentiate each reach at each sampling time.

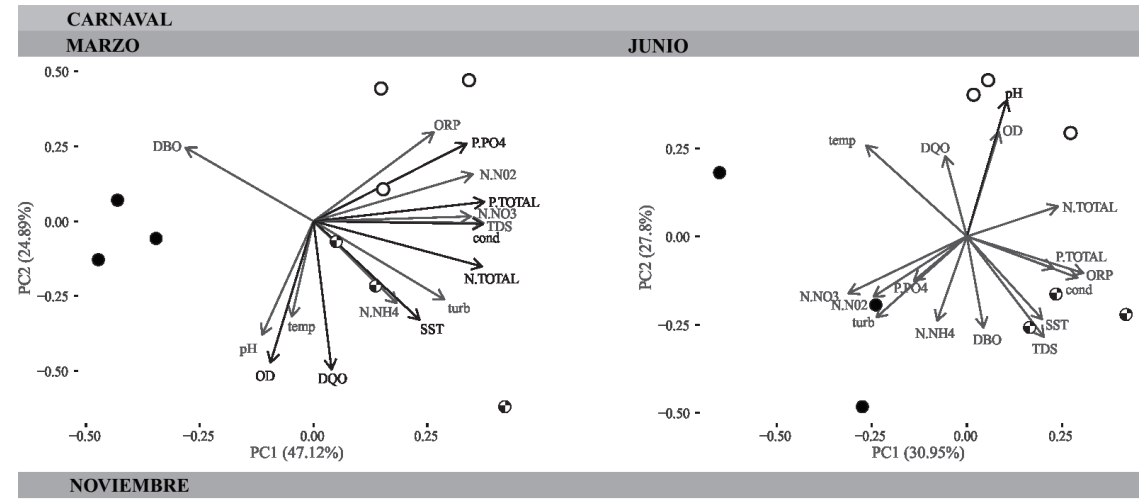

0.75 - 0

0.50

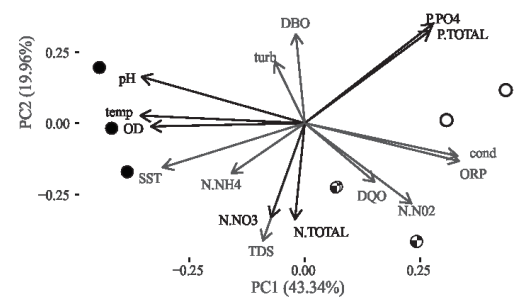

Figura 4. Resultados de los ACP para el cauce Carnaval, por cada período muestreado. Los vectores en negro representan aquellas variables significativas (MANOVA $\mathrm{p}<0.05$ ) para diferenciar los tres tramos (Abajo, Medio, Arriba) en cada momento del año.

Figure 4. PCA results for the Carnaval watershed at each sampling period. Vectors in black represent significantly different variables (MANOVA, $\mathrm{p}<0.05$ ) to differentiate each reach at each sampling time. 
valores de PRS y $\mathrm{P}$ total se asociaron al sitio Abajo, mientras que los de $\mathrm{DBO}$ y $\mathrm{NO}_{2}$-al sitio Medio. En junio, el sitio Arriba estuvo vinculado a los mayores valores de $\mathrm{NO}_{3}^{-}$y $\mathrm{NO}_{2}^{-}$y a los menores valores de PRS. En noviembre, ese sitio mantuvo los valores más altos de $\mathrm{NO}_{3} ; \mathrm{NO}_{2}$, $\mathrm{NH}_{4}{ }^{+}$y $\mathrm{N}$ total, mientras que el PRS aumentó hacia el sitio Abajo.

En el Carnaval (Figura 4), en noviembre, el sitio Abajo tuvo los mayores valores de PRS y P total, mientras que el $\mathrm{NO}_{3}^{-}$y el $\mathrm{N}$ total se vincularon al sitio Medio. En febrero los mayores valores de DQO y $\mathrm{N}$ total se asociaron al sitio Medio, mientras que los incrementos de PRS y $P$ total lo hicieron con el sitio Abajo.

\section{Bacterias indicadoras de contaminación fecal}

En el Chubichaminí, el tramo Medio registra la densidad más altas de $E$. coli en todos los muestreos a excepción de junio, el muestreo que registró las densidades más bajas en todos los arroyos (Figura 5). En el Cajaravillas, el valor más alto de densidad bacteriana se encontró también en el tramo Medio durante el muestreo de marzo. En los arroyos del Gato y Carnaval se registraron las densidades más bajas de $E$. coli en todos los muestreos y no se advierte patrón alguno (Figura 5).

\section{Actividad respiratoria en el sedimento}

La actividad del STE en el sedimento varió entre 0.14-0.16 ( $\pm 0.02-0.05)$ ug INT/mg $\mathrm{cm}^{2} \mathrm{~h}$ en los cuatro cauces estudiados.

En febrero y junio la respiración del sedimento fue mayor en el tramo Medio en comparación con el tramo Arriba de los arroyos Cajaravillas y Chubichaminí, y además en este último fue aún mayor que en el tramo Abajo. En noviembre este patrón se mantuvo en el Chubichaminí, siendo mayor la respiración en el tramo Medio en comparación con los otros dos tramos (Figura 6; Tabla 2). En los arroyos más impactados, la respiración del sedimento fue similar durante

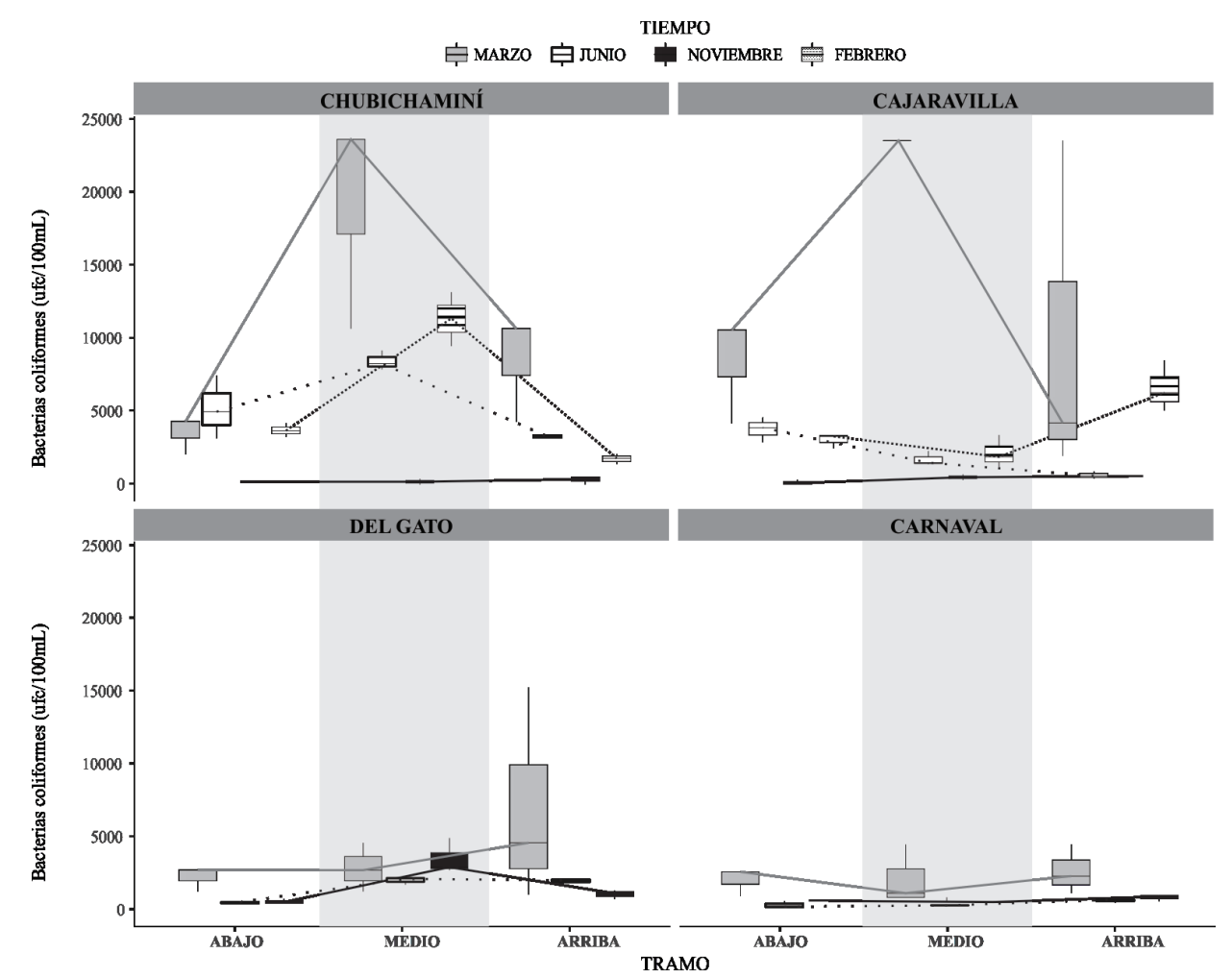

Figura 5. Variación en la densidad de bacterias coliformes fecales (E. coli) en los tres tramos de cada uno de los cuatro cauces en los períodos muestreados.

Figure 5. Variation in bacterial density (E. coli) in all three reaches at each watershed during the four sampled periods. 


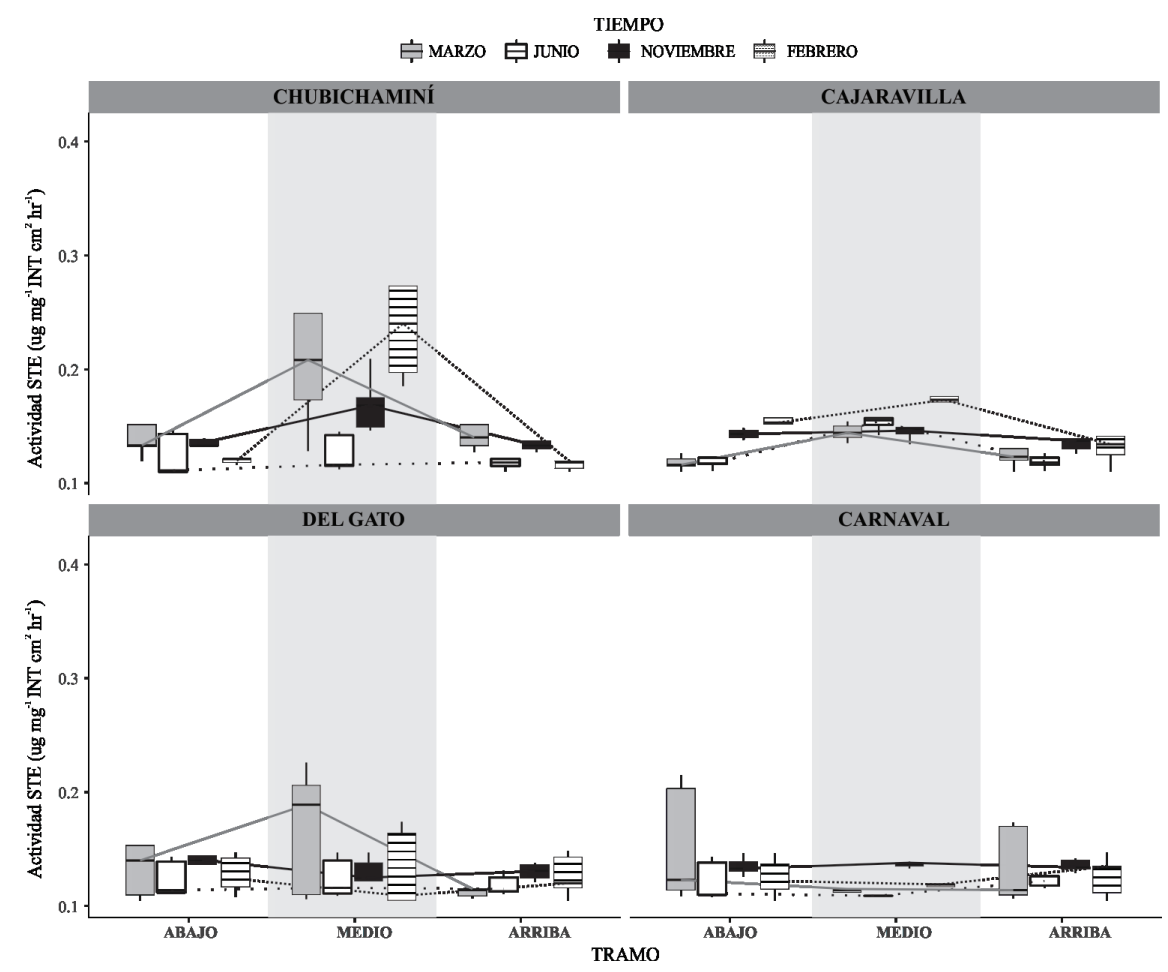

Figura 6. Variación de la actividad del sistema transportador de electrones (STE) en el sedimento de los tres tramos de los cuatro cauces en los períodos muestreados.

Figure 6. Variation in the activity of the electron transfer system (ETS) in the sediment of each reach at each watershed in the four sampling periods.

Tabla 2. Resultados ((F-valor) del ANOVA a 3 vías para las bacterias coliformes y para la medida de respiración del sedimento mediante la técnica de INT-Formazan. Diferencias significativas $(p<0.05)$ se indican con *.

Table 2. Results (F-valor) of the 3-way ANOVA for bacteria and respiratory activity of the sediment through the INT-formazan methodology. Significant differences $(p<0.05)$ are indicated with *.

\begin{tabular}{lcccc}
\hline Variable & CAUCE & TIEMPO & TRAMO(CAUCE) & TRAMO(CAUCE)* TIEMPO \\
\hline Bacterias & $25,084^{*}$ & $43,112^{*}$ & $7,338^{*}$ & $6,361^{*}$ \\
$\begin{array}{l}\text { Actividad } \\
\text { respiratoria }\end{array}$ & $10,187^{*}$ & $6,654^{*}$ & $8,048^{*}$ & $2,164^{*}$ \\
\hline
\end{tabular}

todo el año en todos tramos, con alguna disminución en el tramo Medio en el Carnaval durante marzo.

\section{Metabolismo fluvial}

Las mediciones de metabolismo fluvial de los cauces estudiados indica que son sistemas heterotróficos (R>PPB; Tabla 3). Tanto las PPB como la RE promedio fueron mayores en los cauces mejor conservados, y los valores más negativos de PPN fueron medidos en septiembre en el Cajaravillas y en el Chubichaminí (-33,4 y $-28,6 \mathrm{gO}_{2} / \mathrm{m}^{2} \mathrm{~d}$ respectivamente).

La PPB alcanzó sus valores máximos en el Cajaravillas en septiembre $\left(12,23 \mathrm{gO}_{2} / \mathrm{m}^{2} \mathrm{~d}\right)$. Comparando los cuatro sistemas, la PPN fue mucho menor en el del Gato $(0,31 \pm 0,29$ $\mathrm{gO}_{2} / \mathrm{m}^{2} \mathrm{~d}$ ), aunque en el Carnaval durante el muestreo de febrero los valores de PPN estuvieron también por debajo de $1 \mathrm{gO}_{2} / \mathrm{m}^{2} \mathrm{~d}$. En el Cajaravillas y Chubichaminí los valores de RE también fueron mucho mayores que en el del Gato y Carnaval (Tabla 3), alcanzando valores máximos de respiración de $45,7 \mathrm{gO}_{2} / \mathrm{m}^{2} \mathrm{~d}$ en el 
Tabla 3. Promedios ( $\pm D S$ ) de los parámetros de retención de nutrientes y de metabolismo fluvial en los cuatro sistemas estudiados. As/A: proporción de áreas de almacenamiento de transición sobre el área media; Sw: Distancias de asimilación de $\mathrm{NH}_{4}^{+}$y de $\mathrm{PO}_{4}^{-3}$; Uamb: tasas de asimilación de $\mathrm{NH}_{4}^{+}$y de $\mathrm{PO}_{4}^{-3}$.

Table 3. Mean $( \pm S D)$ for the nutrient retention parameters and fluvial metabolism in all four watersheds. As/A: proportion of transient storage areas in relation to the total mean area; Sw: uptake distances for $\mathrm{NH}_{4}^{+}$and $\mathrm{PO}_{4}^{-3}$; Uamb: uptake rates for $\mathrm{NH}_{4}^{+}$and $\mathrm{PO}_{4}^{-3}$.

\begin{tabular}{rcccc}
\hline & Chubichamini & Cajaravillas & Carnaval & del Gato \\
\hline As/A & 0,33 & 0,35 & 0,09 & 0,04 \\
& $( \pm 0,31)$ & $( \pm 0,19)$ & $( \pm 0,04)$ & $( \pm 0,04)$ \\
NH4-Sw & 12,28 & 41,23 & 15,04 & 10,4 \\
$(\mathrm{~m})$ & $( \pm 12,33)$ & $( \pm 0)$ & $( \pm 16,92)$ & $( \pm 3,39)$ \\
PO4-Sw & 39,62 & 19,96 & 248,48 & 220,07 \\
$(\mathrm{~m})$ & $( \pm 5,11)$ & $( \pm 1,47)$ & $( \pm 331,18)$ & $( \pm 247,59)$ \\
$\mathrm{NH4}$ Uamb & 11,73 & 2,24 & 3,41 & 6,13 \\
$\left(\mathrm{mg} / \mathrm{m}^{2} \mathrm{~min}\right)$ & $( \pm 9,57)$ & $( \pm 3,17)$ & $( \pm 3,6)$ & $( \pm 1,72)$ \\
$\mathbf{P O 4}$ Uamb & 7,35 & 18,94 & 16,67 & $0,71( \pm 19,95)$ \\
$\left(\mathrm{mg} / \mathrm{m}^{2} \mathrm{~min}\right)$ & $( \pm 3,00)$ & $( \pm 5,59)$ & $( \pm 22,29)$ & \\
PPB & 5,16 & 6,66 & 4,03 & 0,31 \\
$\left(\mathrm{~g} \mathrm{O} / \mathrm{m}^{2} \mathrm{~d}\right)$ & $( \pm 5,86)$ & $( \pm 7,88)$ & $( \pm 4,42)$ & $( \pm 0,29)$ \\
$\mathrm{RE}$ & 23,33 & 30,81 & 15,05 & 3,56 \\
$\left(\mathrm{~g} \mathrm{O} / \mathrm{m}^{2} \mathrm{~d}\right)$ & $( \pm 20,66)$ & $( \pm 21,04)$ & $( \pm 0,45)$ & $( \pm 3,75)$ \\
PPN & $-18,18$ & $-24,16$ & $-11,03$ & $-3,25$ \\
$\left(\mathrm{~g} \mathrm{O} / \mathrm{m}^{2} \mathrm{~d}\right)$ & $( \pm 14,79)$ & $( \pm 13,16)$ & $( \pm 3,97)$ & $( \pm 4,04)$ \\
\hline & & & &
\end{tabular}

\section{Retención de nutrientes}

En el tramo Medio del Cajaravillas y del Chubichaminí, la proporción de zonas de almacenamiento transitorio en relación a su ancho (As/A) fue un orden de magnitud mayor que en el Carnaval y en el del Gato (Tabla 3). Las distancias de asimilación de $\mathrm{NH}_{4}^{+}\left(\mathrm{NH}_{4}{ }^{-}\right.$ $\mathrm{Sw}$ ) fueron menores en el del Gato, Carnaval y Chubichaminí que en el Cajaravillas, donde la distancia media de asimilación alcanzó los $41 \mathrm{~m}$ (Tabla 3). Por el contrario, las distancias medias de asimilación de $\mathrm{PO} 4-3\left(\mathrm{PO}_{4}-\mathrm{Sw}\right.$ ) fueron un orden de magnitud menor en los sistemas con bañados mejor conservados (Cajaravillas y Chubichaminí), mientras que en el del Gato y Carnaval llegaron a superar los $390 \mathrm{~m}$ en el período de febrero.

Las tasas de asimilación de $\mathrm{NH}_{4}{ }^{+}$fueron similares en todos los sistemas excepto en el Chubichaminí, cuyos valores fueron mayores a los medidos en los otros sistemas, alcanzando un máximo de $18,5 \mathrm{mg} \mathrm{m}^{2} / \mathrm{min}$. Por otra parte, las tasas de asimilación de $\mathrm{PO}_{4}^{-3}$ en el Cajaravillas $\mathrm{y}$ en el Carnaval tuvieron valores medios mucho mayores a las del sistema del Gato y el Chubichaminí, aunque fueron menos variables en los bañados mejor conservados (Cajaravillas y Chubichaminí).

\section{DISCUSIÓN}

Los resultados muestran que los cuatro sistemas estudiados tienen una importante variabilidad en sus características físicas y químicas durante el año y entre los distintos tramos estudiados. El intercambio entre los ríos y sus planicies aluviales altera las concentraciones de oxígeno disuelto en el curso fluvial principal. En general, en los bañados de inundación se encuentran tasas de respiración más altas que en los cursos fluviales principales, que son las responsables de una disminución en la concentración de oxígeno disuelto (Kobayashi et al., 2011). El ingreso de agua empobrecida en oxígeno que retoma el curso fluvial principal genera disminuciones importantes de oxígeno, que se transfieren aguas abajo sobre todo en períodos 
de aguas bajas, como fue reportado en ríos en Zambia (Zurbrügg et al., 2012), en el Río Paraguay (Hamilton et al., 1995) y en tributarios del Mississippi (Kaller et al., 2015).

Esto es coincidente con los resultados de este estudio, dado que los cauces con BDF mejor conservados disminuyeron la concentración de oxígeno disuelto, la temperatura y el $\mathrm{pH}$, y aumentaron la turbidez, los sólidos suspendidos disueltos y los totales en el agua del curso principal al ingresar ésta a la zona de bañado, manteniéndose esa tendencia aguas abajo. Al contrario, en aquellos cauces con BDF reducidos o degradados, los aumentos significativos en $\mathrm{pH}$, oxígeno disuelto y temperatura se asociaron a los tramos aguas abajo.

\section{Los bañados y sus efectos en la calidad del agua y la dinámica de los nutrientes}

Los bañados de desborde fluviales tienen un rol central en la regulación de la calidad del agua a través de los intercambios entre el agua subterránea y la superficial, la biota y los procesos biogeoquímicos (Yao et al., 2017). Como el agua superficial contiene materia orgánica y oxígeno, mientras que el agua subsuperficial contiene abundantes nutrientes, la mezcla entre ambos sistemas (la zona hiporreica) tiene un impacto importante sobre la calidad del agua y el ciclado biogeoquímico (Marmonier et al., 2012; Sánchez-Pérez \& Trémolières, 2003; Vervier et al., 2009). La interacción agua-sedimento en estos ambientes ayuda a la depuración del agua eliminando nitratos por infiltración a través del sistema suelo-vegetación hacia el agua subterránea, pero también a través de la difusión desde el agua subterránea hacia el agua superficial (Sánchez-Pérez et al., 1991a, 1991b; Takatert et al., 1999).

En las cuencas urbanizadas, los bañados reciben escorrentía superficial o subsuperficial con altas concentraciones de nutrientes, particularmente $\mathrm{NO}_{3}$, y pueden funcionar como sumideros de nitrógeno durante todo el año (Groffman \& Crawford, 2003; Mayer et al., 2007). La remoción de $\mathrm{N}$ en los bañados ocurre principalmente por desnitrificación, un proceso anaeróbico que reduce el nitrato a nitrito, y a los gases óxido nítrico (NO), nitroso $\left(\mathrm{N}_{2} \mathrm{O}\right)$ y dinitrógeno $\left(\mathrm{N}_{2}\right)$, resultando en una permanente pérdida de $\mathrm{NO}_{3}{ }^{-}$del sistema (Paul, 2014). El P, por otro lado, está primariamente vinculado al sedimento, y es removido del agua por sedimentación y procesos de adsorción (Sharpley et al., 2000). Las formas biodisponibles de $\mathrm{P}$ (como por ejemplo Fe-P O Al-P) pueden quedar rápidamente disponibles si las condiciones redox y de $\mathrm{pH}$ cambian (Palmer-Felgate et al., 2011).

En los resultados de esta experiencia, los tramos de cauces con BDF mejor conservados actuaron reteniendo $\mathrm{P}$ (tanto Ptotal como PRS), mientras que en aquellos con BDF degradados y desconectados del agua subterránea, la concentración de este elemento aumentó aguas abajo en el recorrido fluvial. Estos resultados coinciden con los obtenidos en sistemas similares (Bai et al., 2017; Qian et al., 2011; Wang et al., 2013), adonde zonas de bañados actuaron como sumideros de fósforo. Algo similar sucedió con el Ntotal, quedando retenido tanto aguas arriba o en el mismo bañado cuando éste se encuentra bien conservado, ratificando estudios previos que indican el rol de estos ecosistemas en retener nitrógeno (Bernard-Jannin et al., 2016; Jordan et al., 2011; Peyrard et al., 2011). En el caso de las formas de nitrógeno, las diferencias significativas en los cauces con BDF mejor conservados representaron aumentos en las concentraciones de nitrato en los tramos medios o aguas abajo del bañado. En los cauces con BDF peor conservados, por otro lado, los nitratos fueron generalmente más abundantes en tramos aguas arriba del bañado.

\section{La abundancia bacteriana y el metabolismo fluvial en los bañados}

Los patógenos son una de las principales causas de deterioro de la calidad del agua y preocupación de salud pública en todo el mundo. En USA, por ejemplo, representan una de las principales causas de contaminación asociadas con el deterioro de ríos y arroyos, aguas costeras, bahías y estuarios (USEPA, 2017). En nuestro país existe una normativa para el uso seguro de aguas recreativas que establece un nivel guía de 126 ufc/100 mL 
(media geométrica) para $E$. coli, entre otros requerimientos (Ministerio de Salud, Resol 125/2016). El valor promedio obtenido en todos los arroyos relevados en este estudio superan ese nivel guía en los tres tramos.

La densidad de bacterias indicadoras fecales, E. coli en nuestro estudio, está determinada en sistemas fluviales por los diversos procesos que ocurren en las cuencas. Los resultados obtenidos, con densidades más altas en las cuencas con mayor actividad agrícolaganadera reflejan el impacto de esa actividad sobre sus cauces. En las cuencas urbanas estudiadas, en cambio, no se registraron fuentes puntuales tales como descargas de plantas cloacales o industriales. En la escala de una gran cuenca urbanizada, el ingreso de microorganismos fecales por fuentes no puntuales es mucho menor que las por fuentes puntuales. Sin embargo, el impacto local de las fuentes difusas no humanas (especialmente la escorrentía superficial de los campos de pastoreo) puede ser de gran importancia en la calidad microbiológica de los pequeños ríos de cabecera (Collins, 2004; Crowther et al., 2002; Servais et al., 2007). Rochelle- Nevall et al. (2016) demostraron que el uso de la tierra y la hidrología son los principales factores de control de las concentraciones de $E$. coli en el agua de arroyos de la cabecera de una cuenca tropical húmeda, y que la importancia relativa de estos dos factores varía entre las estaciones secas y húmedas. En las cuatro cuencas de este estudio, las concentraciones más altas se observaron durante la estación húmeda, cuando las precipitaciones y la escorrentía fueron más altos. Esto último podría explicar el patrón observado en todos los arroyos, con densidades más altas en períodos de precipitaciones máximas (marzo) y densidades más bajas cuando las precipitaciones son menores (junio).

Los resultados mostraron también un patrón de densidad máxima de $E$. coli en el tramo Medio de los cauces periurbanos caracterizados como BDF mejor conservados. Patrones similares fueron publicados en otros trabajos (Collins, 2004; Scott et al., 2017). Para Collins (2004) las altas densidades de bacterias reflejan la fracción desproporcionadamente grande del flujo superficial y subsuperficial de la cuenca que pasa a través de los humedales $y$, por tanto, actúan como sumideros de microorganismos. El ganado se siente atraído sólo por humedales más pequeños y poco profundos para beber y pastar tanto en verano como en invierno. Por ello, excluyendo éstos últimos, los humedales pueden producir mejoras en la calidad bacteriana del agua, aunque cuantificar con precisión esta mejora es difícil sin estudios a largo plazo.

Trabajos recientes (Neill et al., 2018; Oliver et al., 2018) advierten, sin embargo, sobre la necesidad de identificar con mayor resolución "puntos calientes" o "áreas fuente críticas" en las cuencas que hagan posible la implementación de estrategias eficaces de manejo del impacto sanitario sobre sus cauces.

Las distancias de retención de nutrientes en los BDF bien conservados fueron muy altas comparadas con otros sistemas agrícolas en Norte América, Europa, u Oceanía con rangos similares de descarga en el mundo (ejs., Bernot et al., 2006; Gasparini Fernandes Cunha et al., 2019; Gücker \& Pusch, 2006; Niyogi et al., 2004). En general, los cauces de llanura sin vegetación riparia densa, con buena exposición solar que estimula la producción algal, resulta en sistemas autotróficos (PPB > R; Vannote et al., 1980). Esto puede cambiar en aquellos sistemas alterados por el uso agrícola o urbano, que aporten excesos de nitrógeno, fósforo y/o materia orgánica (Alexander \& Smith, 2006; Dodds, 2006). Estos aportes alóctonos de nutrientes pueden estimular la producción autotrófica bruta, y los ingresos de carbono orgánico pueden acelerar los procesos de descomposición microbiana, incrementando la respiración (Gücker et al., 2006; Wilcock et al., 1998; Young \& Huryn, 1999). Los resultados expuestos en este manuscrito muestran que tanto la producción primaria bruta promedio como la respiración fueron mayores en cauces mejor conservados, resultando incluso en producciones netas (PPB-R) negativas. Esto puede ser explicado por los aportes de carbono orgánico por la vegetación acuática, sobre todo en los tramos medios de los cauces con BDF conservados, sumado a la gran turbidez que limita la producción autotrófica, generan una 
mayor actividad del componente heterotrófico del sistema. Esto ha sido reportado en otros sistemas similares expuestos a impactos agrícolas y urbanos (Wilcock et al., 1998; Gücker et al., 2006; Iwata et al., 2007; Houser et al., 2005). En los ríos impactados por urbanización, la distancia de retención de nutrientes es generalmente mayor que en sistemas poco disturbados (Hall et al., 2013; Meyer et al., 2005). En los resultados expuestos, las distancias de asimilación de $\mathrm{NH}_{4}^{+} \mathrm{y}$ de $\mathrm{PO}_{43}^{-}$fueron hasta un orden de magnitud menores en los bañados mejor conservados, y en el Chubichaminí las tasas de asimilación fueron mucho mayores que en los demás sistemas. Esto indica que el metabolismo de los cauces estudiados muestra que son sistemas altamente activos. Ha habido varios estudios documentando los efectos del uso del suelo agrícola en el tamaño de las zonas de almacenamiento transitorio (ej., Bernot et al., 2006; Weigelhofer, 2017). Nuestros resultados coinciden con aquellos que indican que los cocientes As/A (área de las zonas de almacenamiento transitorio / área total) son significativamente más altos en los sitios menos disturbados (ej., Runkel, 1998; Webster et al., 2003), probablemente debido a una mayor cantidad de arcillas en el cauce.

Coincidentemente, en los cauces con BDF mejor conservados las medidas de respiración microbiana en el sedimento fueron mayores comparados con tramos aguas arriba o aguas abajo de las zonas de desborde fluvial. Por otro lado, en los cauces con BDF degradados la respiración en el sedimento fue homogénea durante todo el recorrido de los tramos analizados. También, las demandas biológicas y bioquímicas de oxígeno (DBO y DQO) en general aumentaron hacia tramos medios o aguas abajo de los BDF bien conservados, mientras que en los cauces con BDF degradados fue muy variable en los distintos momentos del año.

\section{CONCLUSIONES}

Las zonas de bañados de desborde fluvial mejor conservados, comparadas con zonas de bañados degradados por la urbanización:

- Disminuyen el oxígeno disuelto y aumentan la concentración de sólidos suspendidos en el cauce principal. Esto se mantiene aguas abajo de los bañados de desborde fluvial, y está vinculado al aumento de la respiración en los bañados.

- Actúan como sumideros de $\mathrm{P}$ y $\mathrm{N}$, que bajo distintas condiciones físico-químicas pueden volver a solubilizarse en el cauce principal.

- Generan un ambiente propicio para incrementar los procesos metabólicos fluviales, tales como la respiración o la producción primaria, resultando en tasas de asimilación de nutrientes por la biota elevadas.

- Actúan como depuradores de bacterias coliformes en el cauce principal.

Aunque estos patrones fueron generales, hubo mucha variabilidad en los cauces, y los efectos de los bañados sobre el cauce principal dependieron del momento del año y de las condiciones físico-químicas del flujo.

\section{AGRADECIMIENTOS}

Los/as autores/as agradecen a Roberto Jensen por la ayuda en el trabajo de campo, vital para la realización de los muestreos. También agradecen a los revisores por su tiempo y esfuerzo en generar aportes para mejorar el manuscrito sustancialmente. Los estudios fueron financiados por el proyecto de la Agencia Nacional de Promoción Científica y Tecnológica titulado "Estudio hidrológico y ecológico de bañados de desborde para la conservación de sistemas fluviales y mitigación de inundaciones" (PICT-2015-1342), y por el proyecto CONICETPUE titulado "Estudio de lagunas de regulación y bañados de sistemas fluviales, su rol en la integridad ecológica de las cuencas y en la mitigación de inundaciones en la llanura pampeana: medidas para la conservación, rehabilitación y gestión" (2292016010001183).

\section{REFERENCIAS}

Alexander, R. B., \& Smith, R. A. (2006). Trends in the nutrient enrichment of US rivers during the 
late 20th century and their relation to changes in probable stream trophic conditions. Limnology and Oceanography, 51(1 part2), 639-654.

Alexander, R. B., Smith, R. A., Schwarz, G. E., Boyer, E. W., Nolan, J. V. \& Brakebill, J. W. (2008). Differences in phosphorus and nitrogen delivery to the Gulf of Mexico from the Mississippi River Basin. Environmental science \& technology, 42(3), 822-830.

American Public Health Association. APHA, 2012. Standard methods for examination of water and wastewater, method $9221 \mathrm{~B}$.

Bai, J., Ye, X., Jia, J., Zhang, G., Zhao, Q., Cui, B. \& Liu, X. (2017). Phosphorus sorption-desorption and effects of temperature, $\mathrm{pH}$ and salinity on phosphorus sorption in marsh soils from coastal wetlands with different flooding conditions. Chemosphere, 188, 677-688.

Barton, L. L. \& Northup, D. E. (2011). Microbes at work in nature: biomineralization and microbial weathering. Microbial Ecology, 299-326.

Bernard-Jannin, L., Brito, D., Sun, X., Jauch, E., Neves, R., Sauvage, S. \& Sánchez-Pérez, J. M. (2016). Spatially distributed modelling of surface water-groundwater exchanges during overbank flood events-a case study at the Garonne River. Advances in water resources, 94, 146-159.

Bernot, M. J., Tank, J. L., Royer, T. V. \& David, M. B. (2006). Nutrient uptake in streams draining agricultural catchments of the midwestern United States. Freshwater Biology, 51(3), 499-509.

Blenkinsopp, S. A. \& Lock, M. A. (1990). The measurement of electron transport system activity in river biofilms. Water Research, 24(4), 441-445.

Carey, R. O. \& Migliaccio, K. W. (2009). Contribution of wastewater treatment plant effluents to nutrient dynamics in aquatic systems: a review. Environmental management, 44(2), 205-217.

Cochran, W. G. (1951). Testing a linear relation among variances. Biometrics, 7(1), 17-32.

Collins, R., \& Rutherford, K. (2004). Modelling bacterial water quality in streams draining pastoral land. Water Research, 38(3), 700-712.
Covino, T. P., McGlynn, B. L. \& McNamara, R. A. (2010). Tracer Additions for Spiraling Curve Characterization (TASCC): Quantifying stream nutrient uptake kinetics from ambient to saturation. Limnology and Oceanography: methods, 8(9), 484-498.

Crowther, J., Kay, D., \& Wyer, M. D. (2002). Faecal-indicator concentrations in waters draining lowland pastoral catchments in the UK: relationships with land use and farming practices. Water Research, 36(7), 1725-1734.

Dodds, W. K. (2006). Eutrophication and trophic state in rivers and streams. Limnology and Oceanography, 51(1 part2), 671-680.

Dzyuban, A. N. (2003). Bacteriobenthos of the upper Volga Reservoirs as a characteristic of their environmental state. Water Resources, 30(6), 680-688.

Gasparini Fernandes Cunha, D., Finkler, N. R., Gomez, N., Cochero, J., Donadelli, J. L., Saltarelli, W. A., \& Boëchat, I. G. (2019). Agriculture influences ammonium and soluble reactive phosphorus retention in South American headwater streams. Ecohydrology, 13(2)

Geissmann, Q. (2013). OpenCFU, a new free and open-source software to count cell colonies and other circular objects. PloS one, 8(2).

Gerba, C. P., Thurston, J. A., Falabi, J. A., Watt, P. M. \& Karpiscak, M. M. (1999). Optimization of artificial wetland design for removal of indicator microorganisms and pathogenic protozoa. Water Science and Technology, 40:363-368.

Groffman, P. M. \& Crawford, M. K. (2003). Denitrification potential in urban riparian zones. Journal of Environmental Quality, 32(3), 1144-1149.

Gücker, B. \& Pusch, M. T. (2006). Regulation of nutrient uptake in eutrophic lowland streams. Limnology and Oceanography, 51(3), 1443-1453.

Gücker, B., Brauns, M. \& Pusch, M. T. (2006) Effects of wastewater treatment plant discharge on ecosystem structure and function of lowland streams. Journal of the North American Benthological Society, 25(2), 313-329. 
Hall Jr, R. O., Baker, M. A., Rosi-Marshall, E. J. \& Tank, J. L. (2013). Solute specific scaling of inorganic nitrogen and phosphorus uptake in streams. Biogeosciences Discussions, 10(4).

Hamilton, S. K., Sippel, S. J., \& Melack, J. M. (1995). Oxygen depletion and carbon dioxide and methane production in waters of the Pantanal wetland of Brazil. Biogeochemistry, 30(2), 115141.

Hill, V. R. (2003). Prospects for pathogen reductions in livestock wastewaters: A review. Critical Reviews in Environmental Science and Technology, 33:187-235.

Houser, J. N., Mulholland, P. J. \& Maloney, K. O. (2005). Catchment disturbance and stream metabolism: patterns in ecosystem respiration and gross primary production along a gradient of upland soil and vegetation disturbance. Journal of the North American Benthological Society, 24(3), 538-552.

Hunter, R. G., Day, J. W., Lane, R. R., Lindsey, J., Day, J. N. \& Hunter, M. G. (2009). Impacts of secondarily treated municipal effluent on a freshwater forested wetland after 60 years of discharge. Wetlands, 29(1), 363-371.

ISO 9308-1. (2014). Water Quality-Enumeration of Escherichia coli and Coliform Bacteria. Part 1: Membrane Filtration Method for Waters with Low Bacterial Background Flora.

Iwata, T., Takahashi, T., Kazama, F., Hiraga, Y., Fukuda, N., Honda, M. \& Nakamura, T. (2007). Metabolic balance of streams draining urban and agricultural watersheds in central Japan. Limnology, 8(3), 243-250.

Jordan, S.J., Stoffer, J. \& Nestlerode, J.A. (2011). Wetlands as Sinks for Reactive Nitrogen at Continental and Global Scales: A Meta-Analysis. Ecosystems 14:144-155.

Junk, W. J. (2005). Flood pulsing and the linkages between terrestrial, aquatic, and wetland systems. Internationale Vereinigung für theoretische und angewandte Limnologie: Verhandlungen, 29(1), 11-38.

Kaller, M. D., Keim, R. F., Edwards, B. L., Harlan, A. R., Pasco, T. E., Kelso, W. E. \& Rutherford,
D. A. (2015). Aquatic vegetation mediates the relationship between hydrologic connectivity and water quality in a managed floodplain. Hydrobiologia, 760(1), 29-41.

Knox, A. K., Dahlgren, R. A., Tate, K. W. \& Atwill, E. R. (2008). Efficacy of natural wetlands to retain nutrient, sediment and microbial pollutants. Journal of Environmental Quality, 37(5), 1837 1846.

Kobayashi, T., Ryder, D. S., Ralph, T. J., Mazumder, D., Saintilan, N., Iles, J. \& Hunter, S. (2011). Longitudinal spatial variation in ecological conditions in an in-channel floodplain river system during flow pulses. River Research and Applications, 27(4), 461-472.

Kosolapov, D. B., Rogozin, D. Y., Gladchenko, I. A., Kopylov, A. I. \& Zakharova, E. E. (2003). Microbial sulfate reduction in a brackish meromictic steppe lake. Aquatic Ecology, 37(3), 215-226.

Marchetti, Z. Y. \& Aceñolaza, P. G. (2012) Pulse regime and vegetation communities in fluvial systems: The case of the Parana River floodplain, Argentina. Flora-Morphology, Distribution, Functional Ecology of Plants, 207(11), 795-804.

Marmonier, P., Archambaud, G., Belaidi, N., Bougon, N., Breil, P., Chauvet, E., ... \& Dumont, B. (2012). The role of organisms in hyporheic processes: gaps in current knowledge, needs for future research and applications. In: Annales de Limnologie-International Journal of Limnology (pp. 253-266). EDP Sciences.

Mayer, P. M., Reynolds, S. K., McCutchen, M. D. \& Canfield, T. J. (2007). Meta-analysis of nitrogen removal in riparian buffers. Journal of environmental quality, 36(4), 1172-1180.

McIntyre, R. E., Adams, M. A., Ford, D. J. \& Grierson, P. F. (2009). Rewetting and litter addition influence mineralisation and microbial communities in soils from a semiarid intermittent stream. Soil Biology and Biochemistry, 41(1), 92-101.

Meyer, J. L., Paul, M. J. \& Taulbee, W. K. (2005). Stream ecosystem function in urbanizing landscapes. Journal of the North American Benthological Society, 24(3), 602-612. 
Mulholland, P. J. \& De Angelis, D. L. (2000). Surfacesubsurface exchange and nutrient spiraling: Chapter 6. In: Jones, J. B. \& Mulholland, P.J. (Eds.) Aquatic Ecology, Streams and Ground Waters (pp. 149-166). Academic Press.

Mulholland, P. J., Helton, A. M., Poole, G. C., Hall, R. O., Hamilton, S. K., Peterson, B. J., ... \& Dodds, W. K. (2008). Stream denitrification across biomes and its response to anthropogenic nitrate loading. Nature, 452(7184), 202-205.

Neill, A. J., Tetzlaff, D., Strachan, N. J. C., Hough, R. L., Avery, L. M., Watson, H. \& Soulsby, C. (2018). Using spatial-stream-network models and longterm data to understand and predict dynamics of faecal contamination in a mixed land-use catchment. Science of The Total Environment, 612, 840-852.

Nishihama, S., Haraguchi, A., Kawano, T., Michiki, K., Nakazawa, K., Suzuki, T., Uesu, K. \& Yoshizuka, K. (2008). Seasonal changes in the microbial population of the water column and sediments of the Ongagawa River, northern Kyushu, Japan. Limnology, 9(1), 35-45.

Niyogi, D. K., Simon, K. S. \& Townsend, C. R. (2004). Land use and stream ecosystem functioning: nutrient uptake in streams that contrast in agricultural development. Archiv für Hydrobiologie, 160(4), 471-486.

Oliver, D. M., Bartie, P. J., Heathwaite, A. L., Reaney, S. M., Parnell, J. A. \& Quilliam, R. S. (2018). A catchment-scale model to predict spatial and temporal burden of E. coli on pasture from grazing livestock. Science of the Total Environment, 616, 678-687.

Palmer-Felgate, E. J., Mortimer, R. J., Krom, M. D., Jarvie, H. P., Williams, R. J., Spraggs, R. E. \& Stratford, C. J. (2011). Internal loading of phosphorus in a sedimentation pond of a treatment wetland: effect of a phytoplankton crash. Science of the Total Environment, 409(11), 2222-2232.

Parkyn, S. M., Davies- Colley, R. J., Halliday, N. J., Costley, K. J. \& Croker, G. F. (2003). Planted riparian buffer zones in New Zealand: do they live up to expectations? Restoration Ecology, 11(4), 436-447.
Paul, E. (Ed.). (2014). Soil microbiology, ecology and biochemistry. Academic press.

Perryman, S. E., Rees, G. N., Walsh, C. J. \& Grace, M. R. (2011). Urban stormwater runoff drives denitrifying community composition through changes in sediment texture and carbon content. Microbial ecology, 61(4), 932-940.

Peyrard, D., Delmotte, S., Sauvage, S., Namour, P., Gérino, M., Vervier, P. \& Sanchez-Pérez, J. M. (2011). Longitudinal transformation of nitrogen and carbon in the hyporheic zone of an N-rich stream: A combined modelling and field study. Physics and Chemistry of the Earth, Parts $A / B / C$, 36(12), 599-611.

Qian, Y., Liang, X., Chen, Y., Lou, L., Cui, X., Tang, J., ... \& Cao, R. (2011). Significance of biological effects on phosphorus transformation processes at the water-sediment interface under different environmental conditions. Ecological Engineering, 37(6), 816-825.

Riley, A. J. \& Dodds, W. K. (2013). Whole-stream metabolism: strategies for measuring and modeling diel trends of dissolved oxygen. Freshwater Science, 32(1), 56-69.

Rochelle-Newall, E. J., Ribolzi, O., Viguier, M., Thammahacksa, C., Silvera, N., Latsachack, K., ... \& Hmaimum, N. (2016). Effect of land use and hydrological processes on Escherichia coli concentrations in streams of tropical, humid headwater catchments. Scientific reports, 6(1), $1-12$.

Runkel, R. L. (1998). One-dimensional transport with inflow and storage (OTIS): A solute transport model for streams and rivers (Vol. 98, No. 4018). US Department of the Interior, US Geological Survey.

Runkel, R. L. (2007). Toward a transportlbased analysis of nutrient spiraling and uptake in streams. Limnology and Oceanography: Methods, 5(1), 50-62.

Sánchez-Pérez, J. M. \& Trémolières, M. (2003). Change in groundwater chemistry as a consequence of suppression of floods: the case of the Rhine floodplain. Journal of Hydrology, 270(1-2), 89-104. 
Sánchez-Pérez, J. M., Trémolières, M. \& Carbiener, R. (1991a). Une station d'épuration naturelle des phosphates et nitrates apportés par les eaux de débordement du Rhin: La forêt alluviale à frêne et orme. Comptes rendus de l'Académie des sciences. Série 3, Sciences de la vie, 312(8), 395-402.

Sánchez-Pérez, J. M., Trémolières, M., Schnitzler, A., \& Carbiener, R. (1991b). Evolution de la qualité physico-chimique des eaux de la frange superficielle de la nappe phréatique en fonction du cycle saisonnier et des stades de succession des forêts alluviales rhénanes (Querco-Ulmetum minoris IssI. 24). Acta oecologica:(1990), 12(5), 581-601.

Scott, E. E., Leh, M. D. \& Haggard, B. E. (2017). Spatiotemporal variation of bacterial water quality and the relationship with pasture land cover. Journal of Water and Health, 15(6), 839848.

Servais, P., Garcia-Armisen, T., George, I. \& Billen, G. (2007). Fecal bacteria in the rivers of the Seine drainage network (France): sources, fate and modelling. Science of the Total Environment, 375(1-3), 152-167.

Shapiro, S. S. \& Wilk, M. B. (1965). An analysis of variance test for normality (complete samples). Biometrika, 52(3/4), 591-611.

Sharpley, A., Foy, B. \& Withers, P. (2000). Practical and innovative measures for the control of agricultural phosphorus losses to water: an overview. Journal of environmental quality, 29(1), 1-9.

Stream Solute Workshop. (1990). Concepts and methods for assessing solute dynamics in stream ecosystems. Journal of the North American Benthological Society, 9(2), 95-119.

Takatert, N., Sanchez-Pérez, J. M. \& Trémolières, M. (1999). Spatial and temporal variations of nutrient concentration in the groundwater of a floodplain: effect of hydrology, vegetation and substrate. Hydrological Processes, 13(10), 1511-1526.

Tockner, K. \& Stanford, J. A. (2002). Riverine flood plains: present state and future trends.
Environmental conservation, 29(3), 308-330.

Vannote, R. L., Minshall, G. W., Cummins, K. W. Sedell, J. R. \& Cushing, C. E. (1980). The river continuum concept. Canadian Journal of Fisheries and Aquatic Sciences, 37(1), 130-137.

Vervier, P., Bonvallet-Garay, S., Sauvage, S., Valett, H. M. \& Sanchez-Perez, J. M. (2009). Influence of the hyporheic zone on the phosphorus dynamics of a large gravelubed river, Garonne River, France. Hydrological Processes: An International Journal, 23(12), 1801-1812.

Villar, C. A. \& Bonetto, C. (2000). Chemistry and nutrient concentrations of the Lower Parana River and its floodplain marshes during extreme flooding. Archiv für Hydrobiologie, 148(3), 461 479.

Wang, Z., Li, S., Zhu, J. \& Zhang, Z. (2013). Phosphorus partitioning between sediment and water in the riparian wetland in response to the hydrological regimes. Chemosphere, 90(8), 2288-2296.

Webster, J. R., Mulholland, P. J., Tank, J. L., Valett, H. M., Dodds, W. K., Peterson, B. J., ... \& Grimm, N. B. (2003). Factors affecting ammonium uptake in streams-an inter-biome perspective. Freshwater Biology, 48(8), 1329-1352.

Weigelhofer, G. (2017). The potential of agricultural headwater streams to retain soluble reactive phosphorus. Hydrobiologia, 793(1), 149-160.

Wilcock, R. J., Nagels, J. W., McBride, G. B., Collier, K. J., Wilson, B. T. \& Huser, B. A. (1998). Characterization of lowland streams using a single-station diurnal curve analysis model with continuous monitoring data for dissolved oxygen and temperature. New Zealand journal of marine and freshwater research, 32(1), 67-79.

Wollheim, W. M., Vörösmarty, C. J., Bouwman, A. F., Green, P., Harrison, J., Linder, E. \& Syvitski, J. P. (2008). Global N removal by freshwater aquatic systems using a spatially distributed, within-basin approach. Global Biogeochemical Cycles, 22(2).

Wollheim, W. M., Harms, T. K., Peterson, B. J., Morkeski, K., Hopkinson, C. S., Stewart, R. 
J., Gooseff, M. \& Briggs, M. A. (2014). Nitrate uptake dynamics of surface transient storage in stream channels and fluvial wetlands. Biogeochemistry, 120(1-3), 239-257.

Yao, J., Sánchez-Pérez, J. M., Sauvage, S., Teissier, S., Attard, E., Lauga, B., ... \& Gerino, M. (2017). Biodiversity and ecosystem purification service in an alluvial wetland. Ecological Engineering, 103, 359-371.
Young, R. G., \& Huryn, A. D. (1999). Effects of land use on stream metabolism and organic matter turnover. Ecological Applications, 9(4), 1359-1376.

Zurbrügg, R., Wamulume, J., Kamanga, R., Wehrli, B. \& Senn, D. B. (2012). River-floodplain exchange and its effects on the fluvial oxygen regime in a large tropical river system (Kafue Flats, Zambia). Journal of Geophysical Research: Biogeosciences, 117(G3). 